1) дисбалансом вращающихся деталей и неодинаковым весом поступательно движущихся масс;

2) неравномерностью крутящего момента двигателя.

Таким образом, низкочастотные колебания зависят от общей конструктивной схемы двигателя и точности его изготовления и сборки [6].

Если объект подвержен вибрации от периодических сил, то стремятся прежде всего уменьшить их в самом источнике. Для этого повышают точность балансировки вращающихся деталей, точность обработки и чистоту поверхности сопрягающихся деталей, применяют взаимно уравновешивающие механизмы, уменьшают значения действующей на вибрирующую деталь силы и частоты вращения, увеличивают продолжительность рабочего цикла.

Так как вибрационное возбуждение в источнике полностью устранить не удается, то возникает необходимость виброзащиты самого объекта. Ее осуществляют следующими методами:

- присоединяют к объекту упругое подвешенное тело - динамический гаситель, воспринимающий вибрацию основного объекта (динамическое гашение вибрации);

- применяют демпфирование, достигаемое как за счет внутреннего поглощения энергии в материале и конструкции (нанесение слоя упруговязких материалов или применение двухслойных материалов типа сталь - алюминий), так и присоединением специальных демпферов (динамическое поглощение);

- между источником возбуждения колебаний и объектом устанавливают упругие элементы - пружины, резинометаллические виброизоляторы, прокладки из резины и т. п. (виброизоляция) [7].

$$
* * *
$$

1. Михайлов Л. А. Безопасность жизнедеятельности: Учебник для вузов, 2-е изд."Издательский дом "Питер"'. 2012 г. С. 461.

2. KNOWED.RU - Учебные материалы. Режим доступа: http://www.knowed.ru/

3. Анализ характеристик холостого хода дизеля Д-240 при отключении части цилиндров / С. Ю. Федосеев [и др.] // Вестник Челябинской государст-венной агроинженерной академии. - 2011. - № 58. -C. 166-169.

4. Петелин, А. А. Анализнагрузочных характеристик дизеля Д-240 при отключении части цилиндров / А. А. Петелин, С. Ю. Федосеев // ВестникЧелябинскойгосударственной агроинженерной академии. 2011. - № 58. - C. 148-151.

5. ГОСТ Р 52914-2008 Двигатели тракторные и комбайновые. Виброакустические показатели и методы испытаний. 2008. С. 18.

6. Автотранспортный портал. Режим доступа: http://www.nporrtu.ru/

7. Зотов Б. И. Безопасность жизнедеятельности на производстве: Учебник для студентов вузов, обучающихся по специальностям 311300, 311500, 311900/ В.И. Курдюмов.- 2-издание, переработанное и дополненное. - М.: Колос, 2003. 432 c.

\title{
Кондаков А.С. \\ Восстановление момента трения в полимерном подшипнике скольжения по температурным данным
}

Институт проблем нефти и газа СО РАН (Россия, Якутск)

doi: $10.18411 / l j-30-11-2017-52$

idsp: 000001:lj-30-11-2017-52

\section{Аннотация}

Приводится расчётный метод восстановления момента силы трения в полимерном подшипнике скольжения по температурным замерам и его сравнение с экспериментальными значениями при стендовом испытании.

Ключевые слова: полимерный подшипник скольжения, узел трения, температура, момент трения, обратная задача, эксперимент. 
Одним из основных этапов создания подшипников из полимерных материалов, работоспособных в экстремальных условиях, является проведение стендовых и эксплуатационных испытаний. В условиях эксплуатации и при проведении стендовых испытаний не всегда удается получить данные о потерях на трение в подшипниках скольжения, что существенно затрудняет определение основных параметров (например, момента трения), необходимых для прогнозирования их работоспособности и оценки технического состояния. Существующие методы непосредственного замера момента трения предусматривают использование специальных упругих элементов, размещение которых даже в стендовых установках крайне затруднено. С точки зрения доступности, наиболее выгодным являются температурные измерения.

Замеры температуры в том или ином объеме традиционно проводятся практически при любых стендовых испытаниях узлов трения машин и механизмов. Поэтому восстановление потерь на трение по значениям температур, измеряемым в различных точках одного из элементов сопряжения - один из наиболее логических путей повышения информативности испытаний, повышения достоверности технического контроля и диагностики состояния опор скольжения.

В работе $[1,2]$ предложен метод тепловой диагностики трения, позволяющий восстанавливать момент трения по замерам температуры на основе решения обратной задачи теплопроводности. Метод основан на том факте, что практически вся энергия, затрачиваемая на трение, переходит в теплоту [3,4]. Особенностью обратных задач является их некорректность, которая заключается в неустойчивости решения к малым погрешностям в исходных данных, что требует привлечения специальных регуляризующих методов решения.

В данной работе рассматривается наиболее распространённый в машинах и механизмах узел трения - полимерный подшипник скольжения сухого трения. Подшипник скольжения как объект исследования удобен для отработки методики восстановления момента трения, поскольку наряду с простотой геометрической формы для него характерны многие особенности контактного взаимодействия узлов трения.

Рассмотрим схему подшипника скольжения из полимерного антифрикционного материала, представленную на рис. 1. Скольжение происходит по поверхности соприкосновения элементов 1 и 2 с углом контакта $2 \varphi_{0}$. Неподвижная втулка жёстко соединена с обоймой подшипника. Вал вращается с достаточно высокой скоростью, что позволяет тепловой поток на поверхности вала принять равномерно распределённым по окружности.

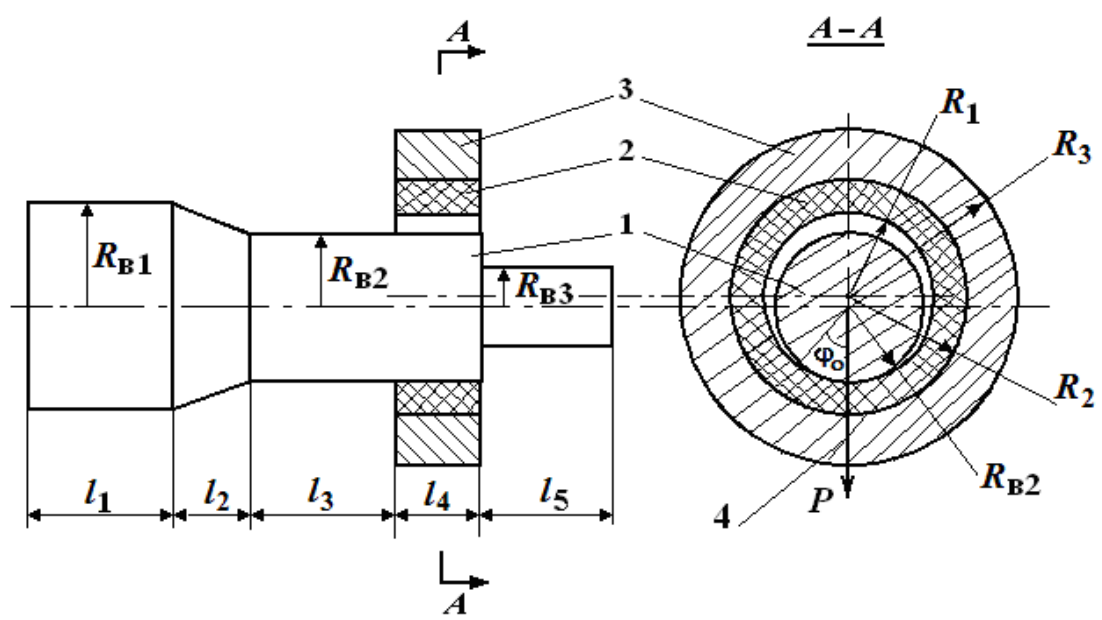

Рис.1. Схема подиипника скольжения: 1 - вал, 2 - полимерная втулка, 3 - обойма, 4-ось нагружения подиипника, $P$ - нагрузка поджатия 
В результате трения в зоне контакта вала с полимерной втулкой происходит тепловыделение с интенсивностью $\mathrm{Q}(\mathrm{t})$. Угол зоны контакта будем считать известным и неизменным в течение времени испытаний. Примем следующие основные допущения: распределение температуры в подшипнике симметрично относительно оси нагружения и однородно по длине; теплообмен с торцов подшипника пренебрежимо мал. Имея в виду существенные различия (до двух порядков) теплопроводностей металлического вала и полимерной втулки будем полагать, что температурное поле в поперечном сечении вала однородным.

Рассмотрим пространственную цилиндрическую систему координат (r, $\varphi, \mathrm{z})$, где ось координаты Oz совпадает с осью вала. Используя принятые допущения, представим втулку и обойму подшипника плоскими, а вал - как стержень (одномерный элемент). Тогда распределение температуры во втулке с обоймой удовлетворяет двумерному уравнению теплопроводности с разрывными при $r=R_{2}$ коэффициентами объёмной теплоёмкости $\mathrm{C}$, и теплопроводности $\lambda$ :

$$
\begin{aligned}
C(T) \frac{\partial T}{\partial t} & =\frac{1}{r} \frac{\partial}{\partial r}\left(r \lambda(T) \frac{\partial T}{\partial r}\right)+\frac{1}{r^{2}} \frac{\partial}{\partial \varphi}\left(\lambda(T) \frac{\partial T}{\partial \varphi}\right), \\
R_{1} & <r<R_{3}, \quad 0<\varphi<\pi, \quad 0<t \leq t_{m},
\end{aligned}
$$

связанному с одномерным уравнением теплопроводности для определения распределения температуры по длине вала

$$
\begin{aligned}
C_{\mathrm{B}}(U) S(z) \frac{\partial U}{\partial t}=\frac{\partial}{\partial z}\left[S(z) \lambda_{\mathrm{B}}(U) \frac{\partial U}{\partial z}\right]-P(z) \alpha_{\mathrm{B}}\left(U-T_{\mathrm{cp}}\right)+ \\
+\Theta(z)\left[Q(t)+\left.2 R_{\mathrm{B} 2} \int_{0}^{\varphi_{o}} \lambda(T) \frac{\partial T}{\partial r}\right|_{r=R_{\mathrm{B} 2}} d \varphi\right], 0<z<L, 0<t \leq t_{m},
\end{aligned}
$$

где $\mathrm{T}(\mathrm{r}, \varphi, \mathrm{t}), \mathrm{U}(\mathrm{z}, \mathrm{t})$ - температуры подшипника и вала, tm- время испытания, $\alpha \mathrm{B}$ коэффициент теплообмена, Tср- температура окружающей среды, L - длина вала, S(z) и $\mathrm{P}(\mathrm{z})$ - функции площади и периметра сечений вала по длине, $\Theta(\mathrm{z})$ равна 1 в точках контакта вала со втулкой и равна 0 в противном случае.

На свободных поверхностях сопряжения задаются обычные условия конвективного теплообмена с окружающей средой. При известной функции интенсивности тепловыделения $\mathrm{Q}(\mathrm{t})$ прямая задача определения нестационарного температурного поля в валу и подшипнике решается методом конечных разностей.

Теперь сформулируем обратную задачу по восстановлению момента трения скольжения в подшипнике. Пусть в полимерной втулке вблизи зоны трения при $\mathrm{r}=\mathrm{R}$, $\mathrm{R} 1<\mathrm{R}<\mathrm{R} 2, \varphi=0$ в течение времени испытаний проведены замеры температуры $T^{e}(t)$.

Обратная задача определения момента трения ставится следующим образом. Восстановить функцию $\mathrm{Q}(\mathrm{t})$ и момент силы трения $\mathrm{M}(\mathrm{t})$, связанные формулой $M(t)=Q(t) R_{1} / V$, из условия минимума функционала

$$
J[Q(t)]=\int_{0}^{t_{m}}\left[T(R, 0, t)-T^{e}(t)\right]^{2} d t
$$

на решениях уравнений (1) и (2) с соответствующими граничными условиями. (Vскорость вращения вала). Функционал (3) характеризует меру уклонения расчётных температур $T(R, 0, t)$ от заданных температур $T^{e}(t)$. 
Такие обратные задачи определения причинной характеристики (тепловыделения) по следственным показателям (температуре) неустойчивы к малым погрешностям в замерах температуры. Поэтому для решения обратной задачи использовался метод итерационной регуляризации на основе градиентных методов минимизации функционала невязки [5]. Градиент функционала (3) определялся, используя сопряженную краевую задачу. Решение модельных задач показали, что разработанный алгоритм позволяет определять функцию тепловыделения $\mathrm{Q}(\mathrm{t})$ c погрешностью сопоставимой $\mathrm{c}$ погрешностью задания температурной информации.

Для проверки эффективности разработанного метода проведена экспериментальная проверка восстановления момента силы трения, изменяющегося во времени, по замерам температуры. Эксперименты проводились по схеме “вал-втулка" на испытательной машине СМТ-1, оснащённой торсионным датчиком трения, при постоянной скорости вращения вала $\mathrm{V}=0,39$ м/с в диапазоне нагрузок $\mathrm{P}=500 \div 1500 \mathrm{H}$. Испытывалась втулка, изготовленная из наполненного фторопласта Ф4К20. Размеры подшипника: $\mathrm{R} 1=13, \mathrm{R} 2=16, \mathrm{R} 3=31$ мм. Размеры вала: $11=22,12=9,13=43$, $14=\mathrm{d}=20,15=26, \mathrm{RB} 1=15, \mathrm{RB} 2=12,5, \mathrm{RB} 3=5,5$ мм. Полуугол контакта $\varphi_{0}=25^{\circ}$. Вал и обойма подшипника изготовлены из металлических материалов. Теплофизические характеристики материалов втулки, обоймы и вала были взяты из справочных источников.

На рис.2 представлены результаты восстановления момента трения по показаниям термопары при $\mathrm{R}=14$ мм. Расчётные значения момента трения с удовлетворительной точностью (10-15 \%) согласуются со значениями, полученными датчиком трения. Экспериментальная проверка показала возможность практического использования предлагаемого метода для восстановления момента трения в реальных сопряжениях.

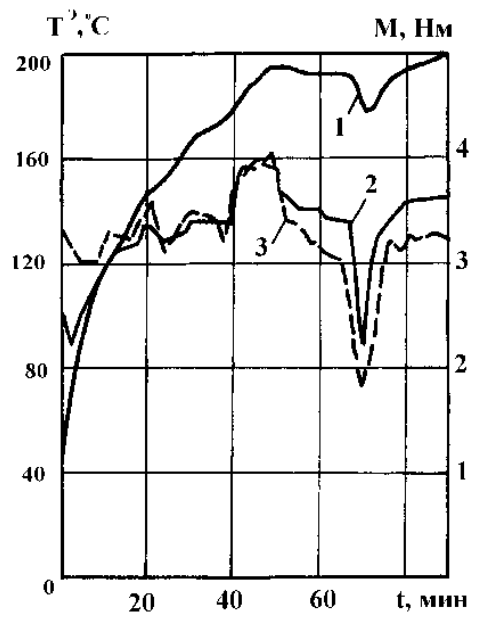

Рис.2. Сравнение экспериментальных и расчётных значений момента трения: 1 - измеренная температура; 2, 3 - измеренные и рассчитанные моменты трения соответственно

Полезность разработанного метода заключается в повышении информативности температурных измерений при эксплуатационных испытаниях узлов трения.

$$
* * *
$$

1. Bogatin O., Chersky I., Starostin N. Simulation and Identification of Nonstationary Heat Transfer in Nonuniform Friction Contact // Trans. ASME. Journal of Tribology. - 1993. - Vol. 115. №2. - P. 299-306.

2. Старостин Н.П., Тихонов А.Г., Моров В.А., Кондаков А.С. Расчет триботехнических параметров в опорах скольжения. - Якутск: Изд-во ЯНЦ СО РАН - 1999. - 274 с.

3. Кузнецов В.Д. Физика резания и трения металлов и кристаллов: Избранные труды. - М.: Наука, 1977. $310 \mathrm{c}$.

4. Костецкий Б.И., Линник Ю.И. Энергетический баланс при внешнем трении металлов // ДАН СССР. 1968. - Т.183, №5. - С. 42-46.

5. Алифанов О.М. Обратные задачи теплообмена. - Москва: Машиностроение. - 1988. - 280 с. 